\title{
SIX SIGMA IN PLASTIC INJECTION MOLDING: REUSE DEFECTIVE PARTS IN NEW ARTICLE PRODUCTION AS RAW MATERIAL INPUT OR NOT?
}

\author{
Meryem ULUSKAN ${ }^{*}$
}

${ }^{1}$ Eskişehir Osmangazi Üniversitesi, Mühendislik Mimarlık Fakültesi,Endüstri Mühendisliği Bölümü, Eskişehir ORCID No: https://orcid.org/0000-0003-1287-8286

\begin{tabular}{ll}
\hline Keywords & Abstract \\
\hline Six Sigma; & In production plants, re-processing of defective products and re-incorporating them into \\
Plastic Injection Molding; & production as raw materials, provides the advantages of reducing scrap and efficient use of \\
Recycling of Scrap Material; & material. However, using recycled defective plastic parts as raw materials in the production of \\
Discoloration Defect; & new parts in plastic injection processes can create aesthetic problems for the final product. On \\
Household Appliances & the other hand, the aesthetic dimension of quality that fulfills customer expectations provides \\
& competitive advantage. Considering this, in this study, the root cause of the aesthetic problem \\
& that occurs as discoloration of a particular component manufactured in a plastic injection \\
& facility operating in the whitegoods industry was revealed and improvement was made. Six \\
& Sigma DMAIC methodology was applied to reduce high scrap rates caused by discoloration \\
& errors, and it was determined that the error was caused by reusing scrap plastic parts as raw \\
& materials in the production of new articles. With the elimination of this cause, the process \\
capability was improved, the 3 sigma process capability was increased to the level of 4.7 sigma & and the aesthetic appearance of the product was improved. This study has shown that the \\
reutilization of defective plastic parts as raw material input in new article production is not a & viable approach for particular products such as whitegoods products.
\end{tabular}

\section{PLASTIK ENJEKSIYYON TESISLERINDE ALTI SIGMA: YENI ÜRÜN ÜRETIMINDE KUSURLU PARÇALAR HAMMADDE OLARAK YENIDEN KULLANILMALI MI?}

\begin{tabular}{l}
\hline Anahtar Kelimeler \\
\hline Altı Sigma;Plastik \\
Enjeksiyon;Hurda Malzemenin \\
Geri Dönüşümü; Renk \\
Bozukluğu Problemi; Beyaz \\
Eşya Sektörü
\end{tabular}

Öz

Üretim işletmelerinde, kusurlu ürünlerin yeniden işlenip üretime hammadde olarak tekrar dahil edilmesi, hurdayı azaltma ve verimli malzeme kullanımı avantajları sağlamaktadır. Bununla birlikte, plastik enjeksiyon süreçlerinde yeni parçaların üretiminde geri kazanılmış kusurlu plastik parçaların hammadde olarak kullanılması nihai ürün için estetik sorunlar yaratabilir. Diğer taraftan kalitenin estetik boyutunun müșteri beklentilerini karşılaması rekabet avantajı sağlamaktadır. Bu göz önüne alındığında, bu çalışmada, beyaz eşya endüstrisinde faaliyet gösteren bir plastik enjeksiyon tesisinde üretimi yapılan bir parçanın renk bozukluğu olarak ortaya çıkan estetik probleminin kök nedeni ortaya çıkarılmış ve iyileștirme yapılmıştır. Renk bozukluğu hatası nedeniyle oluşan yüksek hurda oranlarını azaltmak için Altı Sigma TÜAÍK metodolojisi uygulanmış ve hatanın yeni parçaların üretiminde hurda plastik malzemelerin eritilerek yeniden hammadde olarak kullanılmasından kaynaklandığı tespit edilmiştir. Bu nedenin ortadan kaldırılmasıyla süreç yeteneği geliştirilmiş, 3 sigma süreç yeteneği 4,7 sigma seviyesine çıkarılmış ve ürünün estetik görünümü iyileştirilmiştir. Bu çalışma, beyaz eşya gibi ürünler için, kusurlu plastik parçaların hammadde girdisi olarak üretimde tekrar kullanılmasının uygulanabilir bir yaklaşım olmadığını göstermiştir.

\begin{tabular}{llll}
\hline Araştırma Makalesi & Research Article & \\
BaşvuruTarihi & $: 07.02 .2021$ & Submission Date & $: 07.02 .2021$ \\
Kabul Tarihi & $: 26.07 .2021$ & Accepted Date & $: 26.07 .2021$ \\
\hline
\end{tabular}

*Sorumlu yazar; e-posta :muluskan@ogu.edu.tr 


\section{Introduction}

Plastic has become one of the essential elements of our daily life. At every aspect of life, various plastic products are used. Therefore, plastics manufacturing industry, is among the most prominent industrial sectors in any country (Desai and Prajapati, 2017). The plastic molding and forming sector is a large and diversified one that utilizes plastic materials to manufacture a wide range of industrial and consumer goods. The resultant plastic products are demanded by various markets including automotive, construction materials, appliances, home furnishings, electronics, disposables, houseware and medical products (www.epa.gov, 2020).

Mass production of plastic parts that have complex geometries can be achieved at lower costs via injection molding process where solid plastic pellets are melted, injected into a mold, and then cooled back to a new solid shape (Birley, 2012; Khavekar, Vasudevan and Modi, 2017). Accordingly, injection molding has been extensively utilized for manufacturing of a wide range of plastic parts, extending from the smallest components to large body panels (Maged, Haridy, Kaytbay and Bhuiyan, 2019).

In addition to reduction of production costs, the improvement of molded-parts quality is one of the main goals in injection molding process (Bharti, Khan and Singh, 2011). Quality issues in injection molding can extend from slight surface defects to major problems that can affect the safety, performance and functionality of the product. These issues can stem from the problems related to materials, part design, labor skills, mold design, machine performance and manufacturing conditions (Maged et al., 2019).

As in many manufacturing processes, keeping quality characteristics under control is sufficient in meeting required specifications (Bharti et al., 2011; Desai and Prajapati, 2017). However, large amounts of scrap due to non-conforming parts cannot be avoided in many plastic injection molding operations (Maged et al., 2019). Therefore, any efforts aimed at quality improvement in plastic parts manufacturing operations may result in substantial financial contribution for companies (Desai and Prajapati, 2017). Accordingly, solving quality issues directly affects profits in injection molding companies (Bharti et al., 2011; Desai and Prajapati, 2017).
Considering this direct effect, in this study a thorough Six Sigma DMAIC (Define, Measure, Analyze, Improve, Control) methodology is implemented in an effort to reduce substantial scrap rates due to discoloration in a plastic injection molding plant. The goal of this study was to improve the $3 \sigma$ process baseline to $4 \sigma$ level. In order to achieve the research goal, quality tools such as Pareto chart, work flow, Measurement System Analysis, control charts, Ishikawa diagram, hypothesis tests and process capability analysis were utilized.

The remaining of the paper is as follows; it starts with related literature on the topic, then methodology utilized is introduced. Then analyses and results are presented in detail. Finally, the paper closes with implications, final remarks and future research suggestions.

\section{Literature Review}

\subsection{Six Sigma Research on Plastic Injection Molding}

Six Sigma methodology utilizes a structured framework to improve processes through careful analysis of data and to reduce variation. This customer-driven approach aims at 3.4 defects per million opportunities (Brady and Allen, 2006). In Six Sigma projects, DMAIC steps are followed to identify and solve quality issues (Antony, Snee and Hoerl, 2017). Six Sigma was initially created by Motorola in the 1980s (Antony et al., 2017). Since its launch, Six Sigma has been implemented in many industries (Bharti et al., 2011). As an example, Rahayu and Darvin (2018) achieved substantial quality improvements on ceramic tiles production process with Six Sigma method, whereas, Maia, Pimentel, Silva, Godina and Matias (2019) improved order fulfillment process through Six Sigma DMAIC cycle in the ceramic industry. From a different industry perspective, Hasan, Rahim and Uddin (2013) implemented a successful Six Sigma project in the cement industry.

Because Six Sigma has been utilized for more than 30 years, there is considerable amount of Six Sigma research that focused on manufacturing industries. Nonetheless, studies that specifically address issues encountered in plastic injection molding processes remain limited. For instance, if "process quality" and "plastic injection molding" or "injection molding" combinations are searched in Science Citation Index and Google Scholar databases, not 
many papers that are directly related to the topic are retrieved (e.g. Gordon, 2010; Khan and Acharya, 2016).

Also, if "Six Sigma" and "plastic injection molding" are searched in the scholarly article database of North Carolina State University library, a few direct articles are found (e.g. Safwat and Ezzat, 2008; Kairulazam, Hussain, Mohd Zain, and Lutpi, 2014; Maged et al., 2019; Timans, Ahaus and Antony, 2014; Lo, Tsai and Hsieh, 2009). Examples include Safwat and Ezzat (2008)'s study in which they applied Six Sigma DMAIC methodology to reduce the percentage of scrap materials in a plastic injection molding facility. The primary tools used in this study were Supplier, Input, Process, Output, Customer (SIPOC), Measurement System Analysis (MSA), Failure Mode Effects Analysis (FMEA), pcontrol charts and hypothesis testing. Ultimately, average initial and final scrap rates were compared (Safwat and Ezzat, 2008).

Another example is Kairulazam et al. (2014)'s work in which they present a Six Sigma project implemented for rejection rate reduction in a highgloss plastic molded parts production. The aim of their study was to decrease average rejection rate of $40.6 \%$ to less than $10 \%$. This study achieved a process sigma increase from 1.74 to 3.0 (Kairulazam et al., 2014).

Similarly, in their study Maged et al. (2019) conducted a case study that incorporated Six Sigma DMAIC methodology in plastic injection molding process for quality improvement through defect reduction. The goal of their study was to determine root causes and eliminate major quality issues. The tools utilized in this study included Pareto chart, Statistical Process Control charts, histogram, fishbone-diagram, checklist, Measurement System Analysis and hypothesis tests. As a result of their study, the rejection rate was significantly decreased and the cost of poor quality was reduced by $45 \%$, whereas, sigma level was increased to 4.5 (Maged et al., 2019).

The last direct examples include Timans et al. (2014)'s study in which they utilized design of experiments as a Six Sigma method to improve process quality of injection molding operations within a small and medium sized enterprise (Timans et al., 2014). Similarly, Lo et al., 2009 also utilized design of experiments to screen relevant process parameters in the injection process. The main objective of their study was to enhance the quality of injection-molded lenses through Six
Sigma DMAIC implementation. As a result of this study, process capability index $C_{p u}$ was increased from 0.57 to 1.75 (Lo et al., 2009).

There are a few other studies related to quality implementations on the plastic injection process (e.g. Khavekar et al., 2017; Kim, Kim, Lee and Kwak, 2017). However, these studies did not directly utilize Six Sigma method but instead utilized either design of experiments type tools or other quality improvement initiatives and methods, such as quality function deployment. As an example Khavekar et al. (2017) compared two design of experiments methodologies through implementation in a plastic injection molding unit. In order to explore the root cause of defects and to optimize the process parameters, experiments were conducted within a perfume bottle cap manufacturing company (Khavekar et al., 2017)

Similarly, in their study, Kim et al. (2017) investigated the optimal values of the overall dimensions of an automobile bumper through Six Sigma and design of experiment method. Critical parameters affecting the overall width of product and their optimal values were determined. After incorporating these optimal settings into the production process, the process ability was improved (Kim et al., 2017).

Finally, in their study Koh, Kim and Choi (2008) aimed to reduce the setup time and molded part defects in the injection molding process. They utilized Quality Function Deployment to provide failure factors along with the related process parameters (Koh et al., 2008).

As it can be seen from the previous studies, in addition to the limited number of direct Six Sigma research on plastic injection molding, there is no distinct Six Sigma research that explicitly improves the appearance/aesthetics of the molded plastic parts. Therefore, review of prior literature indicates that further Six Sigma research is required to help companies establishing a systematic approach to quality improvement, especially when aesthetics aspects of the products are considered.

\subsection{Reuse of Defective Plastic Products}

Governments have started to establish environmental and waste management regulations related to the efficient disposal of scrap material. The plastics molding and forming industry is among the industries that have been affected with these 
regulations. Many plastic injection molding processes generate large amounts of scrap material as a result of non-conforming parts manufactured. Generally these scrap material cannot be reused again. Reclaim and reuse of injection molding waste, such as plastic defective parts, can incur high costs and can be very time consuming. (Maged et al., 2019).

Under the environmental and regulatory concerns, in an effort to recover injection molding waste, reuse is a widespread implementation in which discarded or used polymer goods are reutilized (Niaounakis, 2014). Reusing refers to using a part as it is without treatment. Therefore, during reusing practice, rejected preforms, final plastic products or used components are processed as they are, by keeping the chemical structure of the polymer. Because reusing polymers consumes less energy and fewer resources, it is a commonly preferred practice (Niaounakis, 2014).

There are four types of reusing:

i) direct recovery of scrap material during molding (e.g. feedback of used material),

ii) mixing the scrap polymer to be treated with other polymers, generally together with compatibilizers, which exhibit interfacial activities in heterogeneous polymer blends, to manufacture new articles,

iii) blend with various additives, for instance reinforcing agents and antioxidants,

iv) alteration of the polymer structure (e.g. through reactive extrusion) to retrieve its original properties (Niaounakis, 2014).

In the current study, prior to improvement took place, recuperation practice was employed at some extent in an effort to dispose of the scrap material. Therefore, recuperation is briefly explained below:

Recuperation practice is extensively used for industrial scrap recycling purposes. In recuperation process, these industrial residues or parts are cut into small pieces or turned into ground form and are directly utilized in the processing machine along with virgin material. Sprues, defective parts and melt lumps may be sources of scrap material in injection molding. Accordingly, like virgin biopolymers, scrap biopolymers which are produced during injection molding processes may be considered as potential sources for the production of new articles via recycling processes (Niaounakis, 2014).
As a result, utilization of recycled plastic materials is among the means of protecting resources and the environment. Recycled plastic benefits many applications in different industries. However, usage of defective plastic material in injection molding process can create problems during manufacturing processes leading to product-quality challenges. In this study, such quality challenges which cause aesthetics problems for the product is revealed and eliminated through systematic Six Sigma DMAIC implementation.

\section{Methodology}

In order to improve the plastic injection molding process, Six Sigma DMAIC methodology was implemented. Six Sigma implementations aid organizations to create a sustainable competitive advantage focused on quality (Evans and Lindsay, 2014). In Six Sigma, quality issues are handled through a structured framework named DMAIC to discover root causes and realize solutions (Antony et al., 2017). Each stage has various powerful tools and these stage-specific tools offer a variety of techniques to assist process and product improvement efforts (Uluskan, 2016). The DMAIC stages are briefly explained below:

Define: The initial step in DMAIC procedure is to identify the problem. In this phase, project scope is narrowed down with the help of initial analyses, such as Pareto analysis. Then project goal is defined in accordance with the customer requirements. Finally, workflow is created to better understand the process.

Measure: In this step, at first, measurement system is analyzed to assure its accuracy. Then control charts are created to determine any special causes. Finally, process performance is measured through capability analysis.

Analyze: In the analyze step, root causes of variation and defects are investigated through tools such as cause-and-effect diagram.

Improve: In this phase, process performance is improved by addressing and eliminating the root causes. Final process capability is analyzed for comparison.

Control: At this final step, improved process performance is controlled and future process performance is assured. Statistical process control should be used for monitoring process behavior. Final control charts are created. 
In this study, a detailed Six Sigma DMAIC methodology was implemented to improve the quality of molded plastic parts. Six Sigma tools such as work flow, Pareto chart, control charts, Measurement System Analysis, Ishikawa diagram, hypothesis tests, Process Capability Analysis were utilized. The DMAIC steps and analyses are explained in detail in the "Results and Discussion" section. Research and publication ethics were followed in this study. Necessary permits were obtained in October 2019 from the study plant.

\section{Results and Discussion}

\subsection{Define Stage}

In order to determine the product type to be studied, defect data and total sales data were compiled for different stock keeping units (SKUs), i.e. different plastic parts molded, for 9 months between January and September 2019. Then, parts per million (PPM), which is the number of defective units in one million units, values were calculated for these SKUs through Equation 1 given below.

$$
P P M=\frac{\text { total number of defective units }}{\text { sample size }} \times 1,000,000
$$

As a result of this preliminary analysis, 5 SKUs, i.e. plastic parts, with the highest sales volume and PPMs were determined and are given in Table 1.

Table 1

Five SKUs with highest PPM values

\begin{tabular}{lrrr}
\hline SKU number & $\begin{array}{r}\text { Total Sales } \\
\text { Volume }\end{array}$ & $\begin{array}{r}\text { Number of } \\
\text { defective units }\end{array}$ & PPM \\
\hline 10677 & 501354 & 11154 & 22247.75 \\
04597 & 470409 & 4301 & 9143.11 \\
10678 & 499752 & 3348 & 6699.32 \\
09379 & 360263 & 1041 & 2889.56 \\
02821 & 234361 & 53 & 226.15 \\
\hline
\end{tabular}

Based on these total sales volume and number of defective units data, two SKUs, namely 10677Worktop Trim Right and 10678-Worktop Trim Left, which are right-left symmetric components and are manufactured simultaneously on the same machine, were selected for improvement. In addition, since the selected 10677 right and 10678 left components directly affect the product visually, the errors in these parts were easily seen by the customer and caused the rejection of all product batch. These components are the top right and left side components of dryers as shown in Figure 1.

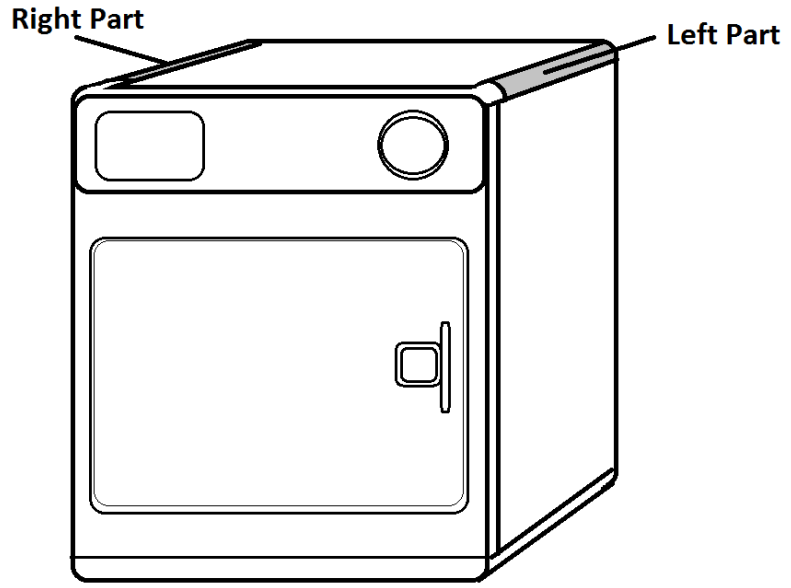

Figure 1. 10677- Right and 10678- Left components selected for improvement 
In order to determine the rates for various defects encountered in these two selected plastic components, Pareto diagrams were created. Main defect types encountered include short shot - in which the final molded part is incomplete after cooling, burrs or flashes - which are excess plastic material appearing as a protrusion at the edge of a component, packaging errors, scratches and finally discoloration. As it can be seen from Figure 2 and
Figure 3, which are the Pareto charts created for 10677-Right and 10678-Left parts respectively, that discoloration defect has the maximum number of defects for both parts. Discoloration occurs when the color of molded part is different than the customer-specified color. In general, this defect negatively affects the appearance of the product especially for white-colored household appliances.

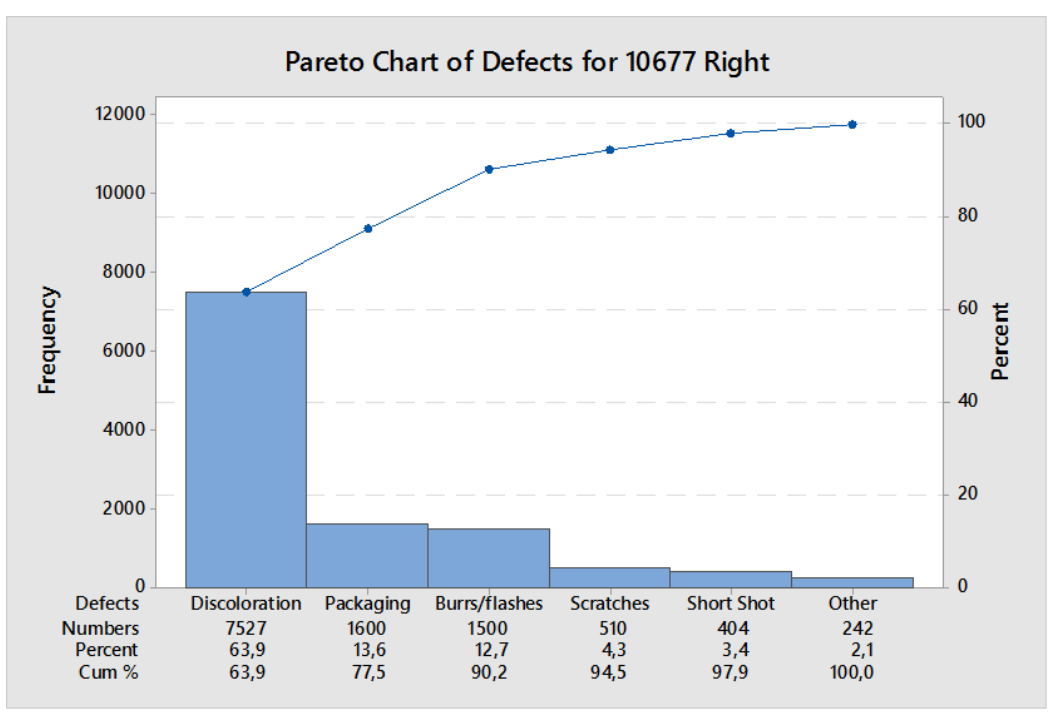

Figure 2. Pareto chart for 10677 right part

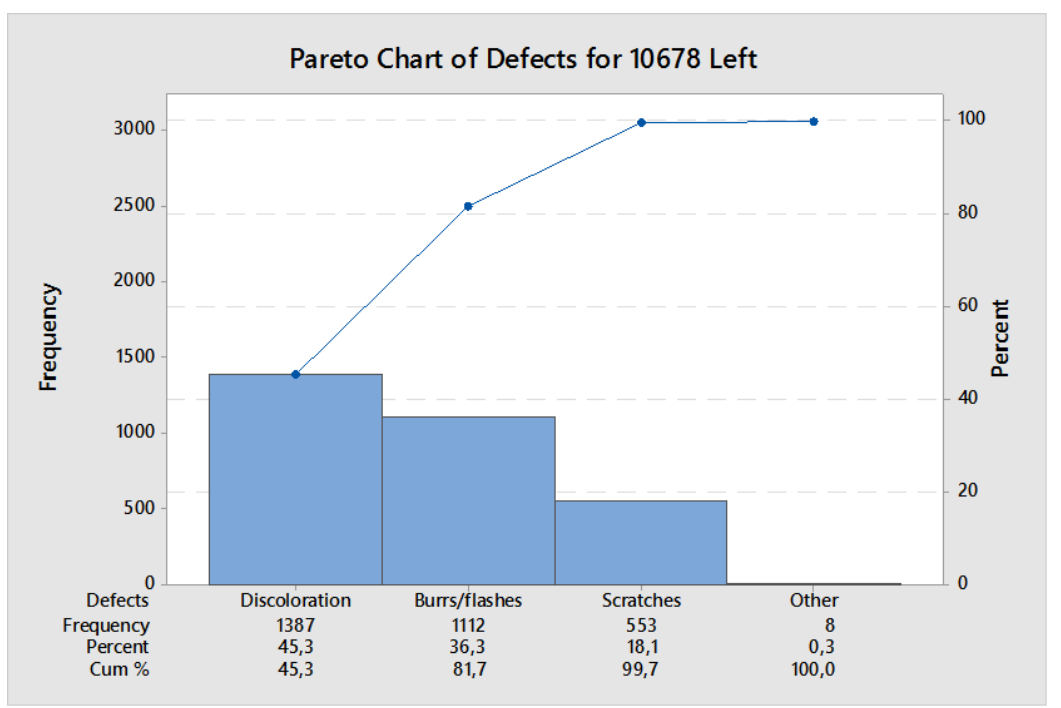

Figure 3. Pareto chart for 10678 left part

Based on these initial analyses, problem statement was created as:

Problem Statement: The plastic injection molding process for 10677-Right and 10678-Left components of the white-colored dryers cannot meet -2.90 and -1.50 specification requirements for color grade and discoloration problem constitutes almost $64 \%$ and $46 \%$ of the overall defects for right and left part respectively. 
Then, goal statement was created based upon this problem statement as:

Goal Statement: To decrease the discoloration defect rate in these components and to increase the initial process capability of 3 sigma level to at least 4 sigma.

\subsubsection{Work Flow Creation}

A thorough work flow diagram was created to determine the steps of plastic injection molding process (Figure 4). Plastic injection molding process mainly involves three basic steps: Initial quality control, injection molding and final quality control.

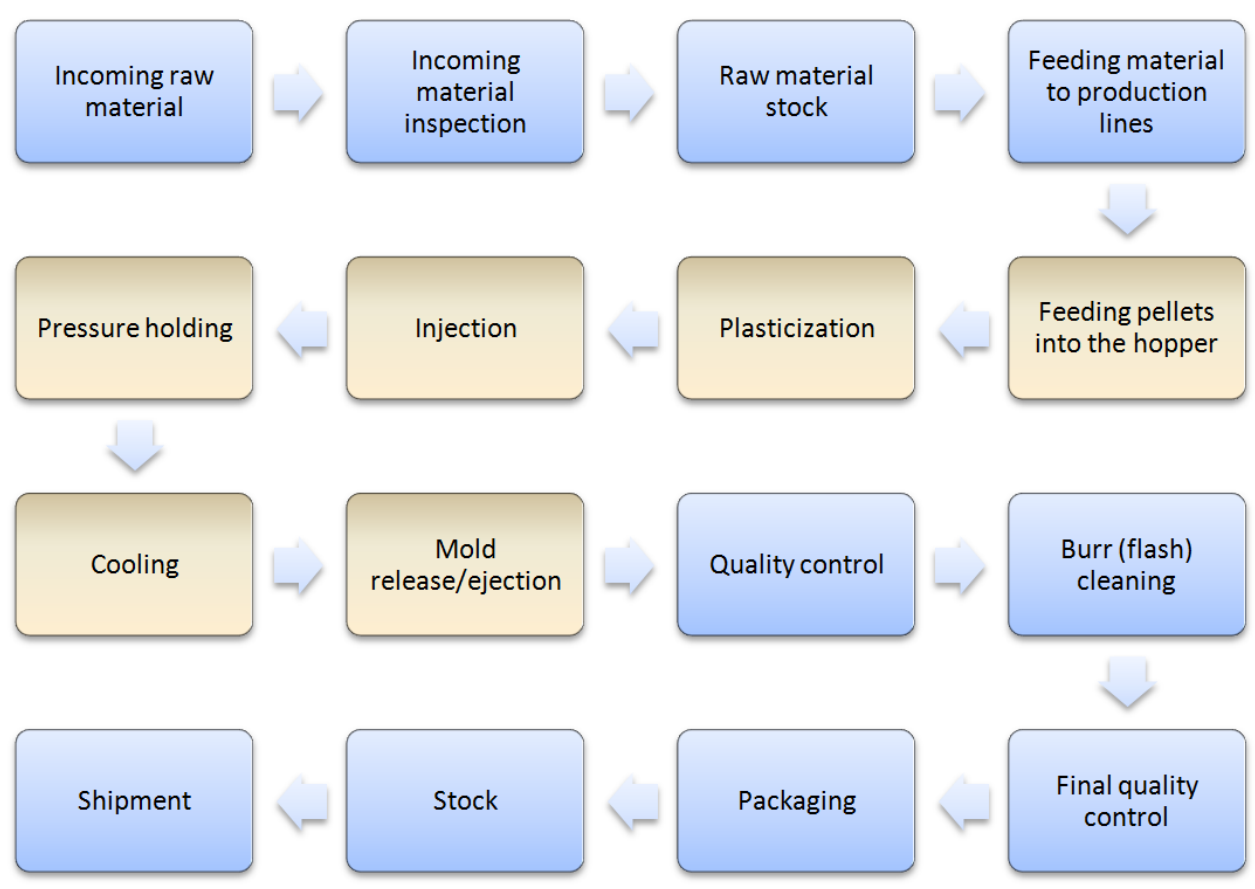

Figure 4. Flow diagram for plastic injection molding process

During injection molding process, solid plastic pellets are melted, injected into a mold, and then cooled back to a solid article. The process consists of five sequential steps including material feeding, plasticization, injection, pressure holding, cooling and mold release (Figure 4). First, the plastic pellets are placed in the hopper through which they are fed into the high-temperature injection barrel (Figure 5). In the injection barrel, plasticization step takes place during which the pellets are heated, melted and plasticized. This hot melted plastic polymer is then pushed to the forepart of the barrel, i.e. the metering zone, with the rotation of the screw or the plunger. The hot melt of plastic is forced into a lower temperature mold-cavity via injection nozzle. Injection of the hot melt into the mold is realized at a high speed under the pushing pressure applied through the screw or the plunger. The screw continuously pushes the hot melt of plastic in the barrel into the mold-cavity for replenishment, because the molten plastic shrinks in the moldcavity due to cooling. During cooling step, the molten plastic at the mold-cavity is cooled into a solid article which has the final shape. In the end, the mold is released, opened and the solid article is taken out from the mold-cavity with the help of the ejector system. 


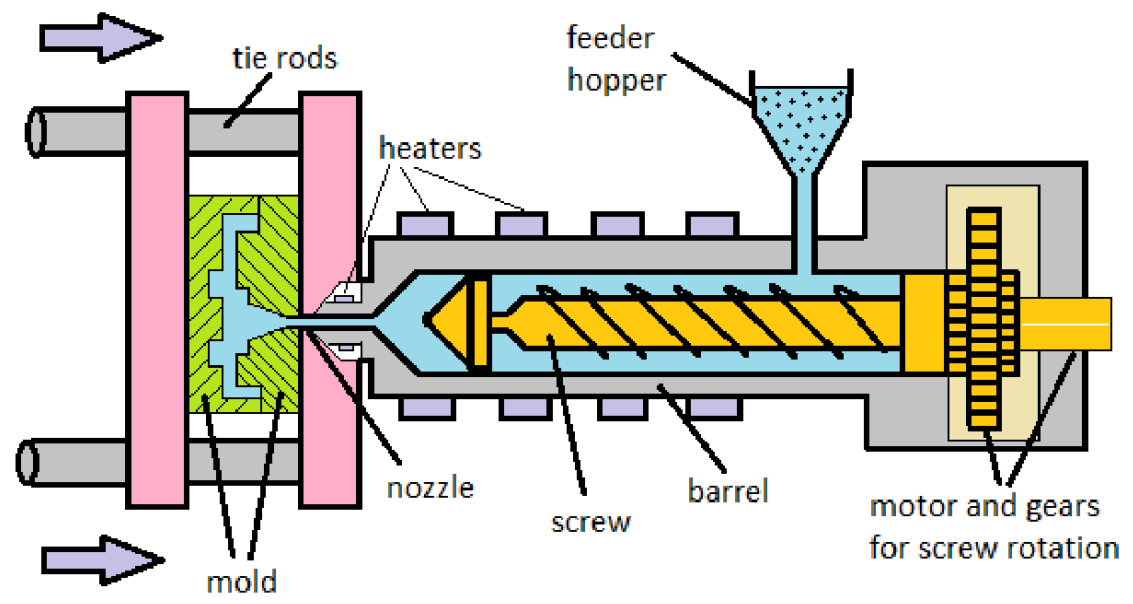

Figure 5. Plastic injection molding machine

After the solid part is ejected from the injection machine, it is gone through physical inspection. Existing burrs or flashes are cleaned if possible. Then, final quality inspection takes place to ensure the complete structure of the article.

After the customer-specified structure is ensured, the molded plastic parts are packaged, stocked in the inventory area, placed in boxes and finally shipped to the customer.

\subsection{Measure Stage}

\subsubsection{Measurement System Analysis}

Measurement System Analysis (MSA) is used to evaluate the capability of a measurement system for a specified process. Therefore, prior to analysis phase, it is necessary to verify that the measurement system is consistent, accurate and can effectively discriminate between different parts. For the Measurement System Analysis, 40 measurements were taken from 10 parts by 2 operators through 2 replicates for both components - left and right parts.

MSA for the component 10677 Right: Analysis of Variance (ANOVA) method was employed for Measurement System Analysis. Initial analysis revealed the fact that the part*operator interaction is not significant at the 0.05 significance level (pvalue is 0.891 ) as seen in Table 2 . For this reason, the final ANOVA table is created by eliminating the interaction term from the model (Table 3 ).

\section{Table 2}

Initial ANOVA table for MSA - 10677 Right

\begin{tabular}{|c|c|c|c|c|c|}
\hline \multicolumn{6}{|c|}{ Initial ANOVA -10677 Right } \\
\hline Source & $\mathrm{DF}$ & SS & MS & F-Value & P-Value \\
\hline Part & 9 & 0.0972125 & 0.0108014 & 385.000 & 0.000 \\
\hline Operator & 1 & 0.0001225 & 0.0001225 & 4.366 & 0.066 \\
\hline Part* Operator & 9 & 0.0002525 & 0.0000281 & 0.449 & 0.891 \\
\hline Repeatability & 20 & 0.0012500 & 0.0000625 & & \\
\hline Total & 39 & 0.0988375 & & & \\
\hline
\end{tabular}


Table 3

Final ANOVA table for MSA (without interaction) - 10677 Right

\begin{tabular}{llllll}
\hline Final ANOVA -10677 Right & & & \\
\hline Source & DF & SS & MS & F-Value & P-Value \\
Part & 9 & 0.0972125 & 0.0108014 & 208.479 & 0.000 \\
Operator & 1 & 0.0001225 & 0.0001225 & 2.364 & 0.135 \\
Repeatability & 29 & 0.0015025 & 0.0000518 & & \\
Total & 39 & 0.0988375 & & & \\
\hline
\end{tabular}

By means of ANOVA, variance components are calculated and these components are utilized to determine the percent of the measurement system variation within the total variation. The Gage Evaluation Table and MSA graphs are provided in both Table 4 and Figure 5.

In gage evaluation table (Table 4), the key metric, i.e. \% Study Variation for Total Gage R\&R $\left(\% S V_{\text {TotalGageR\&R }}\right)$ was found as $14.21 \%$, which means that $14.21 \%$ of overall variation in color grading occurs due to measurement errors. According to the analysis result, the measurement system was acceptable since $\% S V_{\text {TotalGageR } \& R}$ value was less than $30 \%$, which is the general acceptance limit for MSA studies.

Table 4

The results of the MSA for the component 10677 Right

\begin{tabular}{lrrr}
\hline Gage R\&R - 10677 Right & & & \\
\hline Source & StdDev (SD) & Study Var. & \%Study Var. \\
Total Gage R\&R & 0.0074394 & 0.044636 & 14.21 \\
Repeatability & 0.0071979 & 0.043188 & 13.74 \\
Reproducibility & 0.0018800 & 0.011280 & 3.59 \\
$\quad 0.0018800$ & 0.011280 & 3.59 \\
Oart-To-Part & 0.0518401 & 0.311041 & 98.99 \\
Total Variation & 0.0523712 & 0.314227 & 100.00 \\
Number of Distinct Categories & $=9$ & & \\
\hline
\end{tabular}




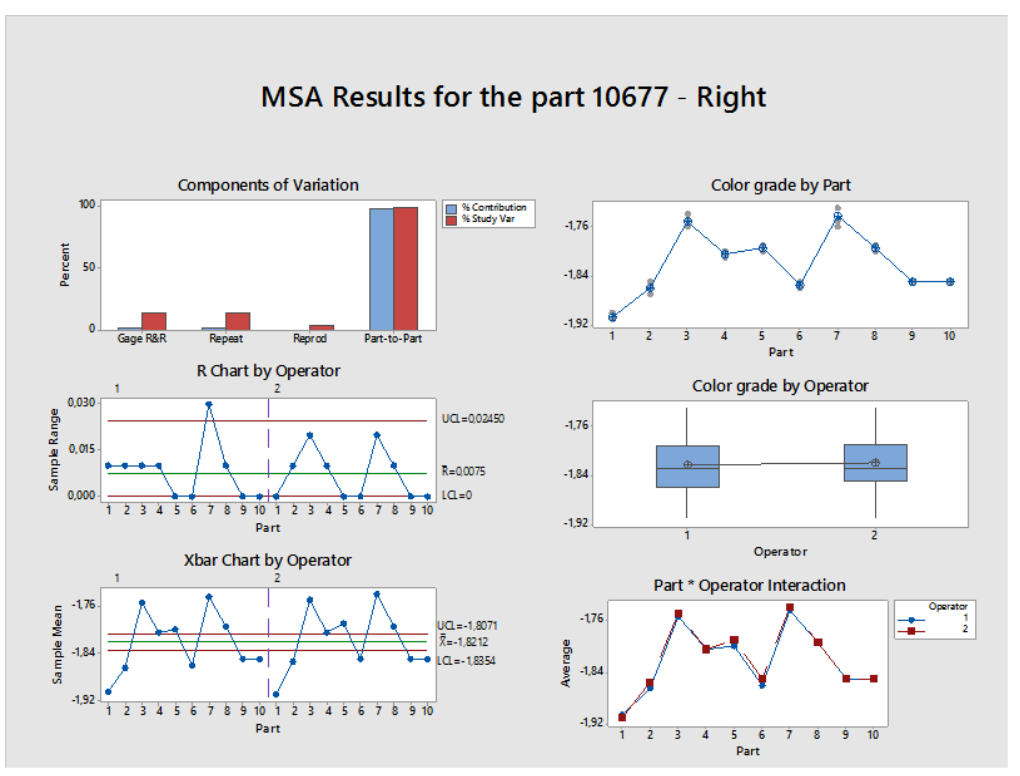

Figure 5. The results of the MSA for the component10677 Right

MSA for the component 10678 Left: Similarly, another MSA is conducted using variance analysis method for the left part. During initial analysis, no significant interaction is found with a p-value of
0.281 for part*operator interaction (Table 5). Again, final ANOVA table is created by removing the interaction term (Table 6).

Table 5

Initial ANOVA table for MSA - 10678 Left

\begin{tabular}{lrrrrr}
\hline Initial ANOVA for MSA - 10678 Left & & & \\
\hline Source & DF & SS & MS & F-Value & P-Value \\
Part & 9 & 004950 & 0.0055000 & 206.250 & 0.000 \\
Operator & 1 & 0.00001 & 0.0000100 & 0.375 & 0.555 \\
Part* Operator & 9 & 0.00024 & 0.0000267 & 1.333 & 0.281 \\
Repeatability & 20 & 0.00040 & 0.0000200 & & \\
Total & 39 & 0.05015 & & & \\
\hline
\end{tabular}

Table 6

Final ANOVA table for MSA (without interaction) - 10678 Left

\begin{tabular}{lrrrrr}
\hline Final ANOVA for MSA - 10678 Left & & & \\
\hline Source & DF & SS & MS & F-Value & P-Value \\
Part & 9 & 0.04950 & 0.0055000 & 249.219 & 0.000 \\
Operator & 1 & 0.00001 & 0.0000100 & 0.453 & 0.506 \\
Repeatability & 29 & 0.00064 & 0.0000221 & & \\
Total & 39 & 0.05015 & & & \\
\hline
\end{tabular}


Again, variance components are calculated through ANOVA outputs. The Gage Evaluation Table and MSA graphs are given in both Table 7 and Figure 6.

$\% S V_{\text {TotalGage } \& R}$ was found to be $12.59 \%$ which is less than $30 \%$ and the measurement system was found to be satisfactory (Table 7). Repeatability was
$12.59 \%$, whereas, reproducibility was $0 \%$. On the other hand, variation due to part-to-part was $99.20 \%$ as desired. Lastly, the number of distinct categories was 11, also indicating satisfactory gage capability.

Table 7

The results of the MSA for the component $10678 \mathrm{Left}$

\begin{tabular}{lrrr}
\hline Gage R\&R - 10678 Left & & & \\
\hline Source & StdDev (SD) & Study Var. & \%Study Var. \\
Total Gage R\&R & 0.0046978 & 0.028187 & 12.59 \\
$\quad$ Repeatability & 0.0046978 & 0.028187 & 12.59 \\
Reproducibility & 0.0000000 & 0.000000 & 0.00 \\
$\quad$ Operator & 0.0000000 & 0.000000 & 0.00 \\
Part-To-Part & 0.0370065 & 0.222039 & 99.20 \\
Total Variation & 0.0370065 & 0.223821 & 100.00 \\
Number of Distinct Categories $=11$ & & \\
\hline
\end{tabular}

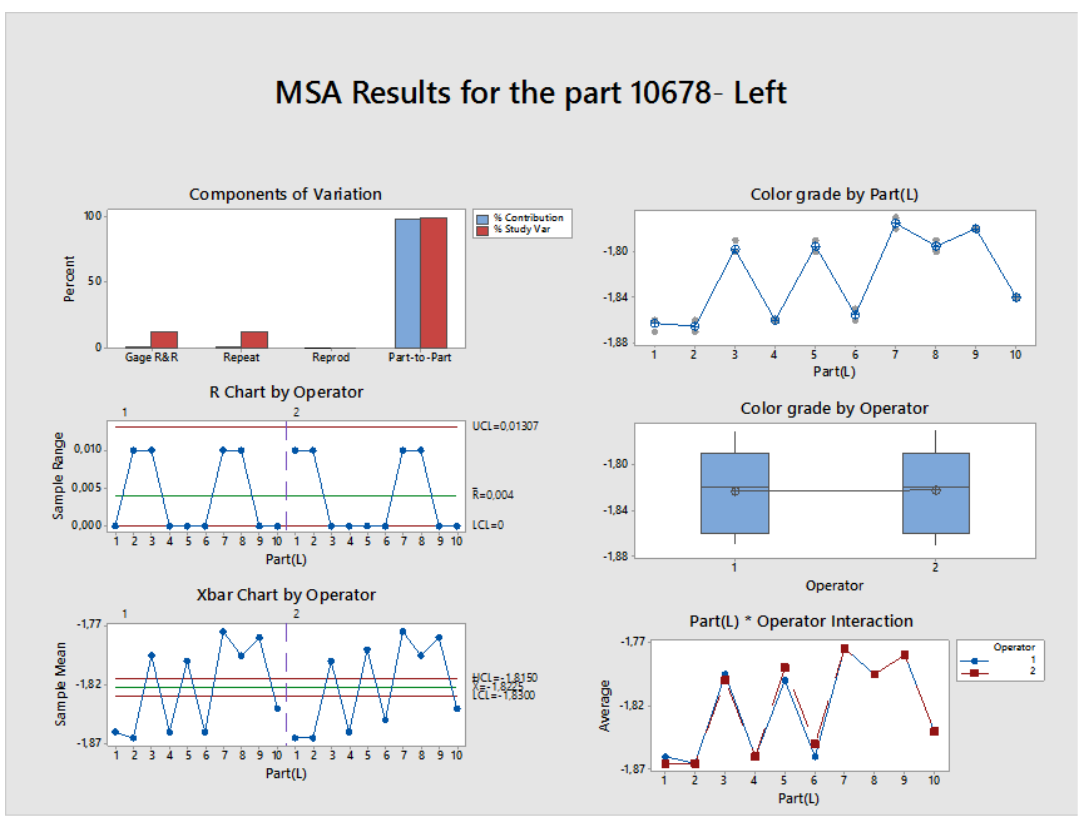

Figure 6. The results of the MSA for the component10678 Left

\subsubsection{Control Charts Prior to Improvement}

After the determination of gage capability, data were gathered for 10 consecutive manufacturing hours. Every hour, a sample size of 10 parts, for both left and right, were taken, making up a total of 100 measurements for each part.
In order to determine whether there exist special causes of variation, $\bar{X}-S$ control charts were created with Minitab $^{\circledR}$ software (Figure 7 and Figure 8). In these charts $\bar{X}$ and $S$ values for 10 samples $(m=10)$ each of size $n=10$ were plotted for both right and left parts. 


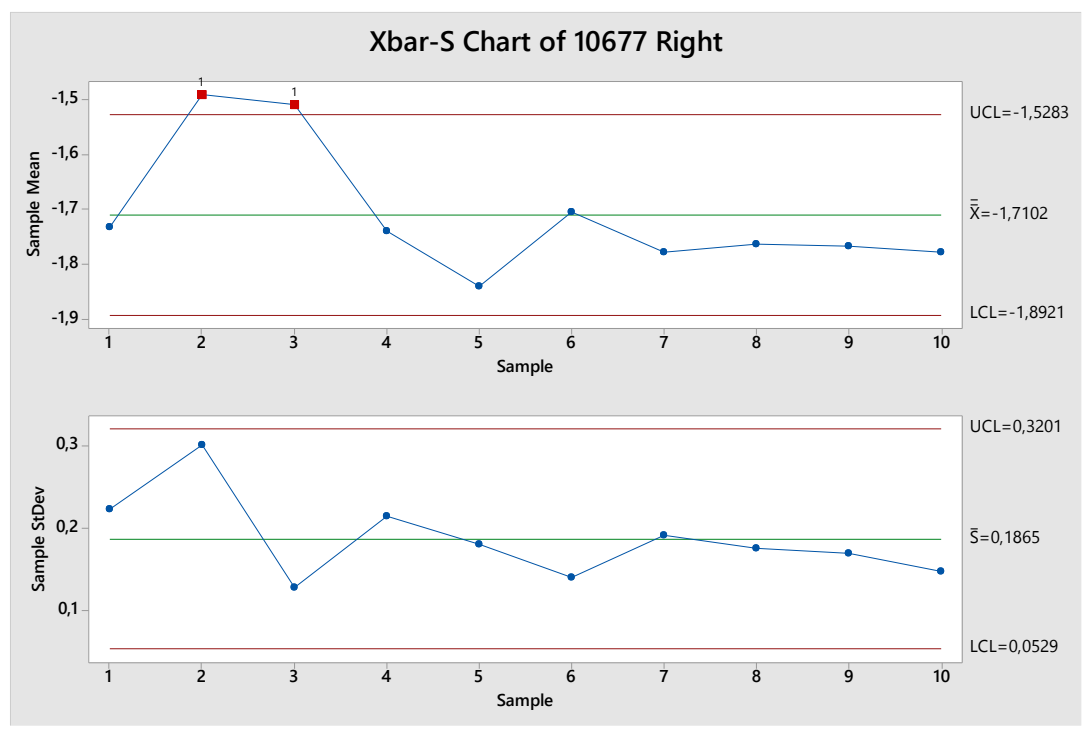

Figure 7. Initial $\bar{X}-S$ charts for the component 10677 Right

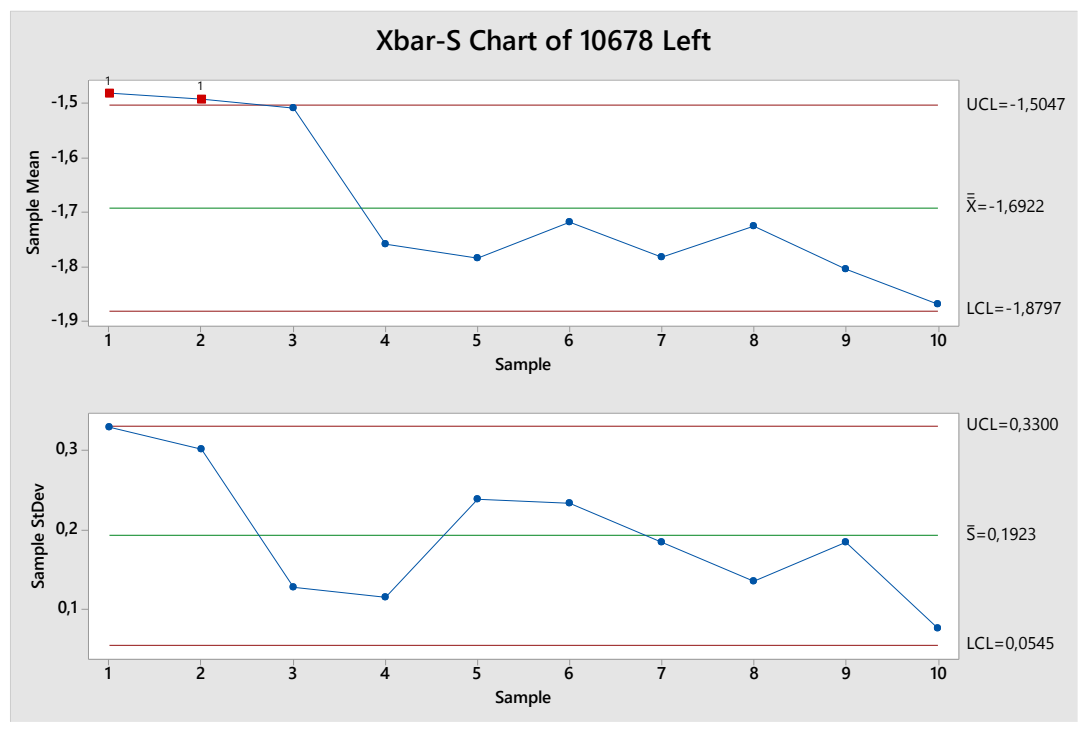

Figure 8. Initial $\bar{X}-S$ charts for the component 10678 Left

When $\bar{X}-S$ charts are observed, it can be seen that a small number of points appear to exceed the control limits. Investigation of the special causes demonstrated that the initial samples, i.e. $2^{\text {nd }}$ and $3^{\text {rd }}$ samples for the right component and the $1^{\text {st }}$ and the $2^{\text {nd }}$ samples for the left component, are out of control limits due to operator error occurred at the beginning of that shift. Accordingly, control charts were re-drawn for both components by eliminating these three initial samples (Figure 9 and Figure 10). Final $\bar{X}-S$ charts showed that all points were within the control limits for both components.
In the initial $\bar{X}$ charts for both parts, 7 consecutive points on one side -below- of the average represent small shifts that are maintained over time. A change in the raw material could cause these smaller shifts. Moreover, both initial $\bar{X}$ and $S$ charts represent that the process is slowly trending down. These could be due to the temperature effects, either cooling or heating, or operator fatigue. However, when out-ofcontrol points, i.e. the three initial samples, are eliminated and charts are re-created, it is seen that these issues, i.e. several consecutive points below the average and trending down issues, mostly vanish showing that processes and molded-product 
quality get more stable as the shift continues. Finally, small trending down pattern may still result from the decreasing attentiveness or motivation of the operators due to fatigue, as the end of that particular shift approaches. This creates a negative impact on the quality of the part molded.

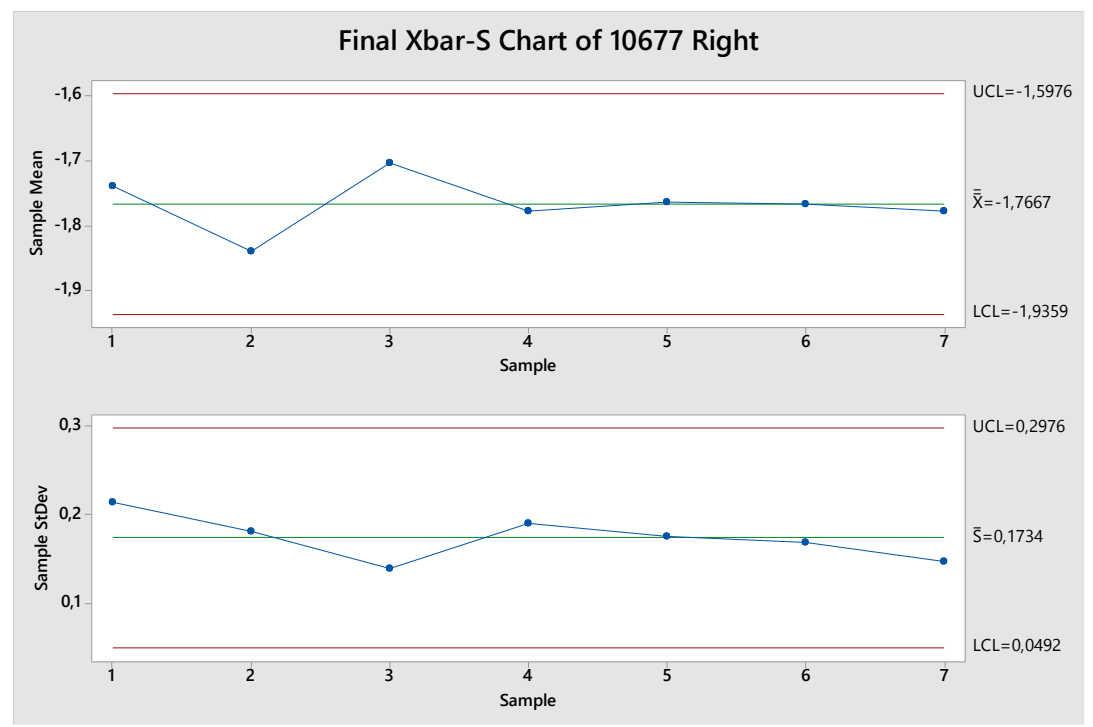

Figure 9.Final $\bar{X}-S$ charts before improvement (special causes excluded) for the component 10677 Right

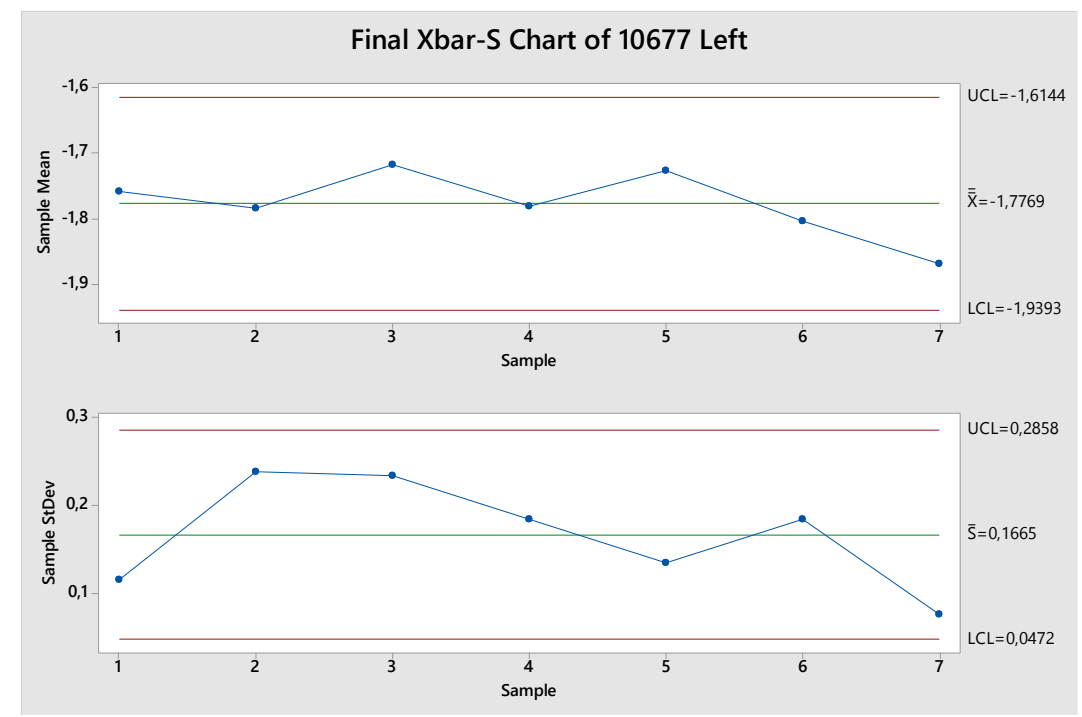

Figure 10.Final $\bar{X}-S$ charts before improvement (special causes excluded) for the component 10678 Left

\subsubsection{Process Capability Analysis Prior to Improvement}

In this stage, process outputs are measured to determine its variability and to compare that variability to a particular specification. Therefore, process capability analysis, which assesses the conformity of the process with customer's specification limits, is an essential part of quality improvement initiatives. For this reason, after it is verified through control charts that the injection molding process is stable, process capability is analyzed. The plastic injection molding process has specification limits of -2.90 and -1.50 for color grade and discoloration.

In order to conduct capability analysis, for 7 hours, a sample size of 10 parts, for both left and right, 
were taken, making up a total of 70 measurements for each part. Because the assumption of normality is required to be met prior to capability analysis, Anderson-Darling test for normality is performed. The normality assumptions were verified for both components, 10677 Right and 10678 Left, since their p-values were 0.413 and 0.065 respectively and larger than the significance level of 0.05 . Then capability analysis were performed and the $C_{p}, C_{p k}$, $P_{p}$ and $P_{p k}$ values are calculated via Minitab ${ }^{\circledR}$ software (Figure 11 and Figure 12).

Process Capability for the 10677 Right Component: The $C_{p}$ value, which is the ratio of specification interval to $6 \sigma$ process variation, was
1.33 initially for the process (Figure 11). The $C_{p}$ values greater than 1.33 are acceptable and greater values indicate better process capability. The $C_{p}$ value of 1.33 shows that the process variation is acceptable when compared to specification interval. On the other hand, $C_{p k}$ value, which assesses the closeness of the current process mean to the upper and lower limit, was calculated as $\min \left(C_{p l}=\right.$ 2.15; $C_{p u}=0.52$ ) $=0.52$. Because $C_{p u}=0.52$, the process center is close to the upper specification limit. Also, a $C_{p k}$ value of $<1.0$ indicates that the process is not capable of meeting its specifications, which was the case in the process prior to improvement.

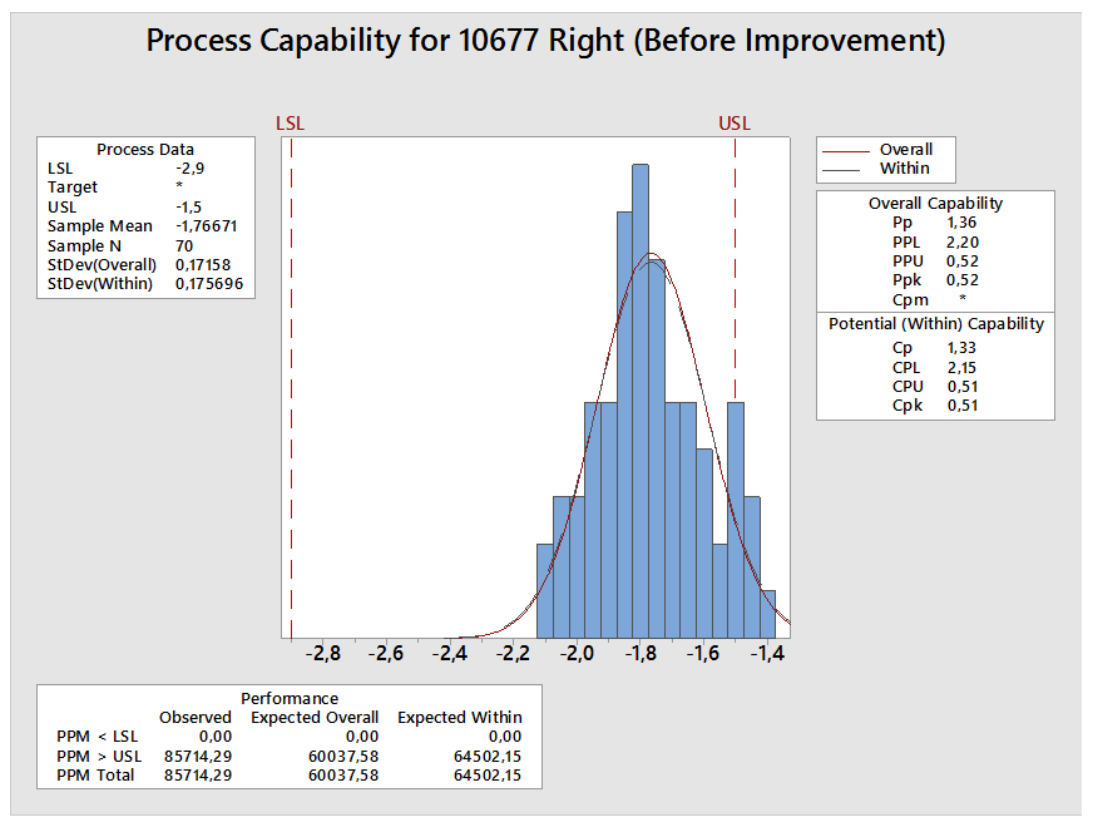

Figure 11. Initial process capability analysis for the component 10677 Right

Along with $C_{p}$ and $C_{p k}$, other process capability indices, such as $P_{p}$ and $P_{p k}$, should be also analyzed to determine the actual capability of the process. $P_{p k}$ value takes into account the process center and the overall variation for all measurements taken. On the other hand, $P_{p}$ evaluates the capability based only on the process variation. Therefore, both $P_{p}$ and $P_{p k}$ values are also examined.

Generally, for a capable process, $P_{p}$ and $P_{p k}$ values should be equal to or greater than 1.33 . For the initial process, the $P_{p}$ value was 1.36 (Figure 11) indicating that specification interval was larger than the overall process variation which is desirable. However, a $P_{p k}$ value of 0.52 was below the standard value of 1.33 and improvement could be achieved by moving process center toward the nominal value, i.e. center of the specification limits. Because $P_{p u}=$ 0.52 was smaller than $P_{p l}=2.20$ value, it was obvious that defective units generated by the initial process exceeded the upper specification limit. Ultimately, a short term sigma level of 3.1 was established.

Process Capability for the 10678 Left Component: Similarly, for the left component capability indices are calculated as follows: $C_{p}=1.32$ and $C_{p k}=0.52, P_{p}$ $=1.34$ and $P_{p k}=0.53$ (Figure 12). Similar comments can be made for the left component, 
because the values of the capability indices of both

left and right components are alike.

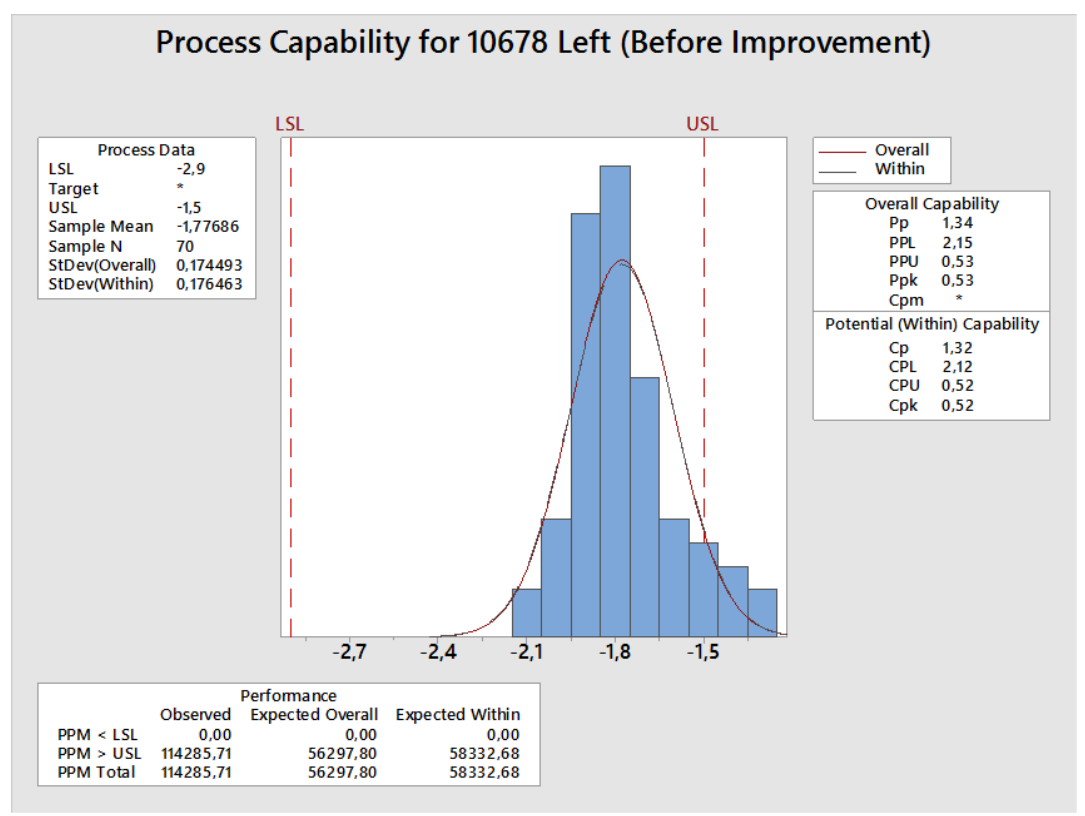

Figure 12. Initial process capability analysis for the component $10678 \mathrm{Left}$

As a result of these initial capability analyses, $3 \sigma$ value was established for the short term process performance.

\subsection{Analyze Stage}

\subsubsection{Ishikawa Cause and Effect Diagram}

An Ishikawa chart was created to categorize the potential causes of the discoloration problem. Discoloration in molded-plastic articles may stem from different reasons, which may comprise several components of injection molding process such as machine, raw materials and method, etc.

As it can be seen in Figure 13, potential root causes of discoloration problem that are listed under injection molding machine may include equipment age, temperature control failure and equipment not being clean. Observations on the equipment, barrel and heater revealed the fact that there were no obvious issues related to molding machine as the molding machinery is not old; the equipment, including barrel and heater, is properly cleaned after every molding process; purging compound is utilized whenever color changes are necessary; and proper functioning of the heater is assured through control at the beginning of every shift. Also maintenance of the equipment takes place on a regular and frequent basis. Therefore, machine related aspects were determined as not being root causes of discoloration problem.

Similarly, no issues were detected with methods related to injection process, screw speed and barrel/nozzle temperature. Injection process settings, such as pressure and speed, were controlled regularly and adjustments were made if necessary. In addition, screw speed and barrel/nozzle temperature are strictly monitored. Therefore, process parameters, including injection time, injection speed, injection pressure, screw speed and barrel/nozzle temperature were all kept at required optimum values revealing the fact that there exist no issues with method.

Manufacturing environment was also observed to determine whether any dirt, dust or foreign substances exist in the production areas. Because the plant has a proper $5 \mathrm{~S}$ implementation in place, the manufacturing environment was found to be clean and no foreign substances were present near the machines. Consequently, environmental issues were determined as not being the root cause of discoloration problem.

Potential root causes that are listed under material consists of plastic pellet or granule characteristics, such as contamination and moisture content, and 
recuperation, which is the reutilization of scrap material together with virgin material as raw material input to the production. Observations revealed the fact that there exist no packaging or storage issues leading to high moisture content or contamination of plastic granules. However, high recuperation rate in the raw material was determined to significantly deteriorate the color of the molded-product and determined as the primary cause of discoloration.
In addition to using recuperated mixture in the production, human errors, i.e. operator errors, were among the main causes of discoloration. Plastic parts with different colors were produced on the same molding machine and an operator is responsible for three different machines where color settings and parameters are entered manually by the same operator. Therefore, during changeover from one color to another, color adjustment errors due to operator may occur.

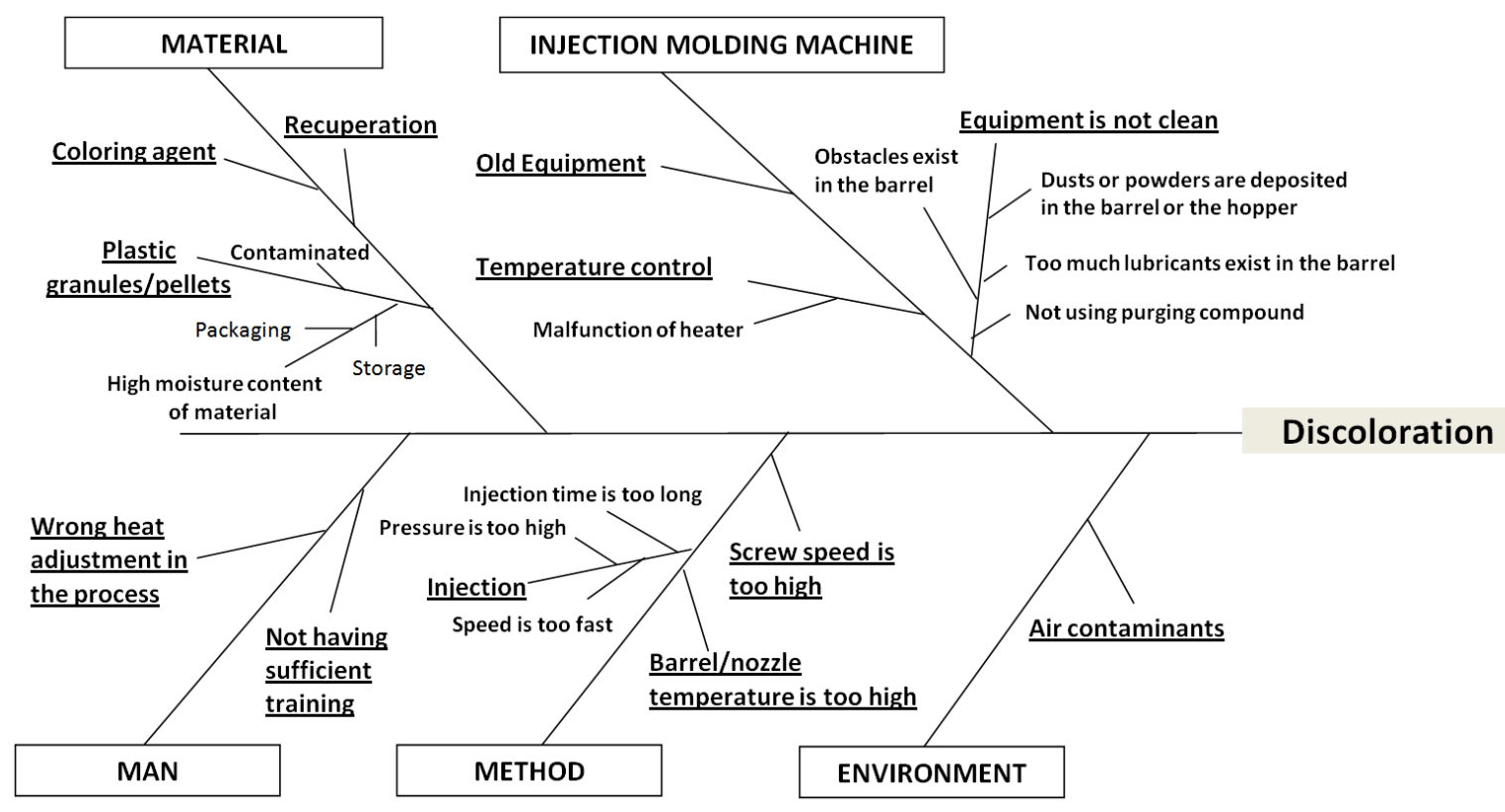

Figure 13. Cause-and-effect diagram for discoloration problem

\subsection{Improve Stage}

\subsubsection{Usage of Recuperated Mixture}

In the analyze phase, it has been determined that material is the main cause for discoloration. The raw material, which was used for the production of 10677 Right and 10678 Left parts, was sent by the customer - the household appliances manufacturer company. This raw material was a mixture of scrap material and virgin material, i.e. original plastic pellets. The customer company added 20 percent of scrap materials into the virgin polymer to reduce the cost of the raw material.

Scrap polymers generated by the molding processes can be possible inputs for the production of new parts. Therefore, recuperation is extensively used to recycle industrial scrap. During recuperation practice, these scrap plastic parts are crushed into granular or ground form and are directly used in the injection molding equipment along with the virgin material. Sprues, defective parts and melt lumps may be sources of scrap material in injection molding.

By reusing scrap material, waste amounts and raw material costs are decreased by the companies that manufacture plastic parts. Therefore, plastic injection companies mix these scrap material with original raw materials at certain rates for recycling purposes and cost issues. Similarly, our study parts 10677 Right and 10678 Left are produced in this way where defective plastic parts are cut into small pieces or crushed into ground, mixed with virgin pellets at $20 \%$ rate and sent to the production lines to be reused in the form of recuperated mixture. The usage of recuperated mixture has been determined as the main cause for discoloration. Since the produced part is used in white colored dryers and the use of melted scrap material as raw 
material in the production of these parts creates a deterioration in the final color, no mixture with scrap material was requested in the raw material. Therefore, it was decided together with the buyer company, i.e. customer, to completely utilize $100 \%$ virgin polymer pellets in the plastic molding process.

\subsubsection{Operator Error}

In addition to using recuperated mixture, human errors due to injection molding machine operators were among the main causes of discoloration. Plastic parts with different colors are produced on the same molding machine and an operator is responsible for three different machines where color settings and parameters are entered manually by the same operator. Therefore, during changeover from one color to another, color adjustment errors due to operator may occur. In order to prevent this error, operators were provided with a refresher training on the topic and also, color parameter cards were prepared and placed at a visible point near the injection molding machines for the ease of use.

\subsubsection{Hypothesis Testing For Significance of Improvement}

After improvements, i.e. i) utilization of $100 \%$ virgin polymer pellets as the raw material in the plastic molding process and ii) preparation of color parameter cards along with operator training, were in place, data on defective parts were compiled. Initially, before improvement, among 70 parts gathered for both right and left parts, a total of 16 defective parts which had discoloration problem were determined. After improvement, none of the 140 compiled parts exceeded the specification limits in terms of color grading. Therefore, hypothesis test was conducted to determine whether improvement was statistically significant. Null and alternative hypotheses were as follows:

$H_{0}: p_{1}=p_{2}$

$H_{1}: p_{1}>p_{2}$
The p-value for the hypothesis test for difference in proportions was $\sim 0.00$ which is smaller than the 0.05 significance level (z-value 4.12). Therefore, the null hypothesis is rejected and it is concluded that the improvement made was significant.

\subsubsection{Process Capability Analysis After Improvement}

Process capability analysis was performed following the improvements made in the process. As it can be seen from the analysis results shown in Figure 14 and Figure 15 that, the final $C_{p}$ value is 1.34 for the right part and 1.76 for the left part, both of which are greater than 1.33. However, $C_{p}$ value works best with a process that is centered at nominal value, because it doesn't tell anything about the location of the process data. In our case, because both processes are not perfectly centered between the specification limits, $C_{p k}$ value should be also reported. In Figure $10 \mathrm{a}-\mathrm{b}$, the final improved $C_{p k}$ values for both right and left parts are 1.07 and 1.17 , respectively, and are in the range of 1.00-1.33, indicating that the process should be strictly controlled, i.e. closely monitored.

Similarly, $P_{p}$ and $P_{p k}$ values are also improved for the process. As seen in Figure 14 and Figure 15 that $P_{p}$ and $P_{p k}$ values are 1.38 and 1.11 for the right and 1.37 and 0.91 for the left part. $P_{p k}$ values are greater than 1.33 which is desired. On the other hand, $P_{p k}$ values indicate that there is still room for improvement. Therefore, because the process center (for both parts) is close to the upper specification limit, further improvements can be made to shift the process center to the nominal value.

Finally, the Expected Within PPM value is also reported along with $C_{p}, C_{p k}, P_{p}$ and $P_{p k}$ values. This value was found to be 634.21 for the right part and 220.28 for the left part which is much better. As a result, a process performance level of $4.7 \sigma$ is established after improvement took place. The increase from $3 \sigma$ to $4.7 \sigma$ level shows that the enhancement in process quality was substantial. 


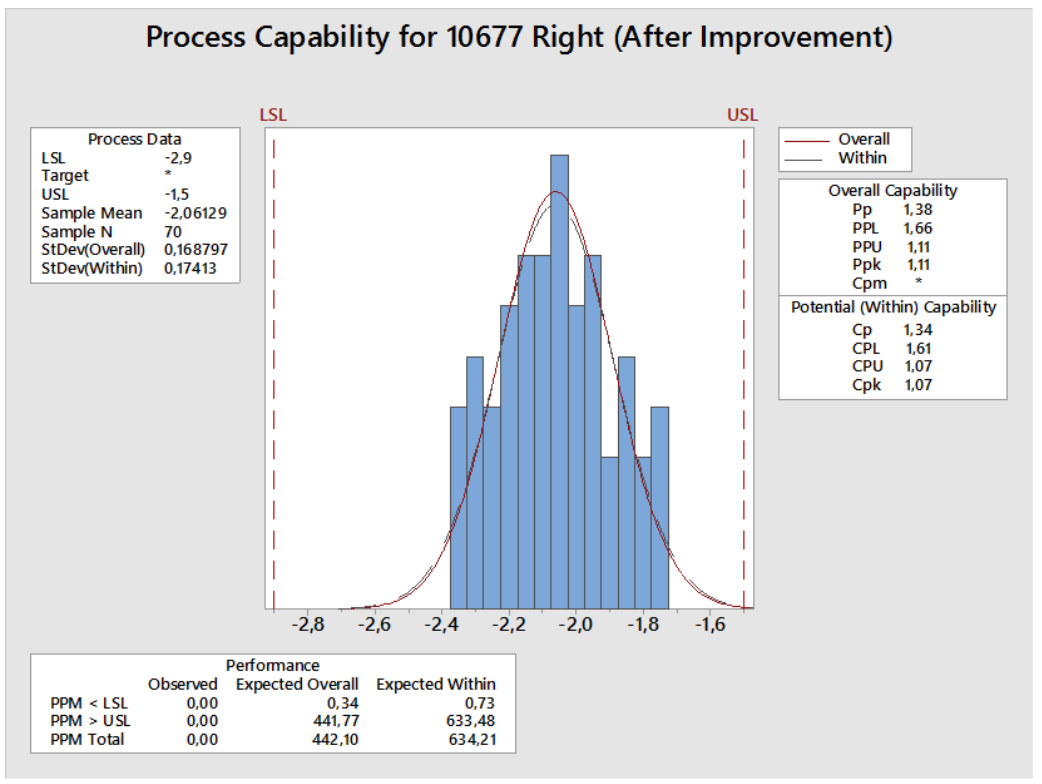

Figure 14. Final process capability analysis for the component 10677 Right

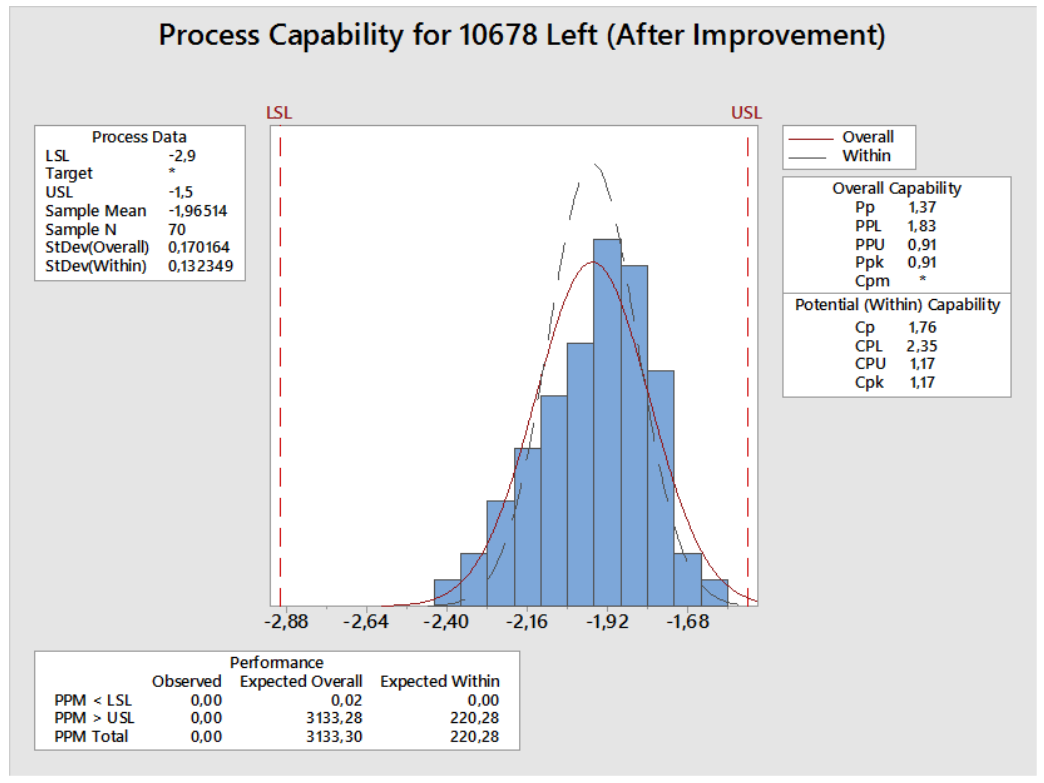

Figure 15. Final process capability analysis for the component $10678 \mathrm{Left}$

\subsection{Control}

\subsubsection{Control Charts and Cost Analysis After Improvement}

In order to monitor the process after the improvement, data were collected over 7 consecutive hours within a particular shift. Each hour, a sample size of 10 parts, for both left and right, were collected. As a result, 70 measurements were obtained for each part to create $\bar{X}-S$ graphs, which are shown in Figure 16 and 17. When the graphs are examined, it can be seen that the plastic injection process is under control with no special causes present. 


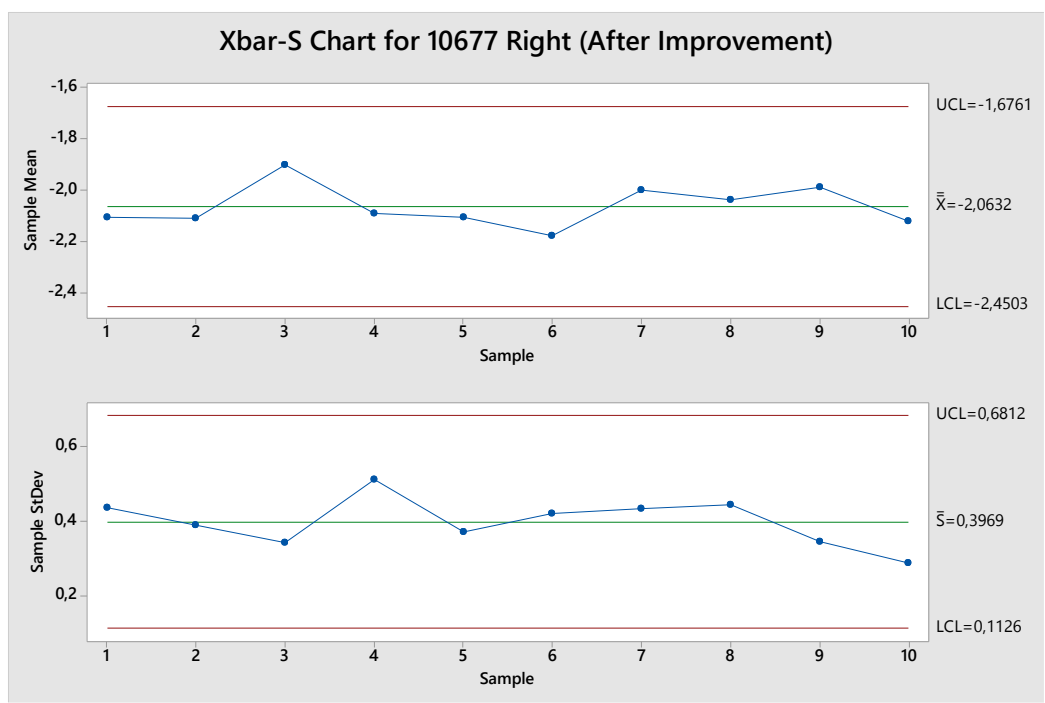

Figure 16. Final $\bar{X}-S$ charts for the component 10677 Right

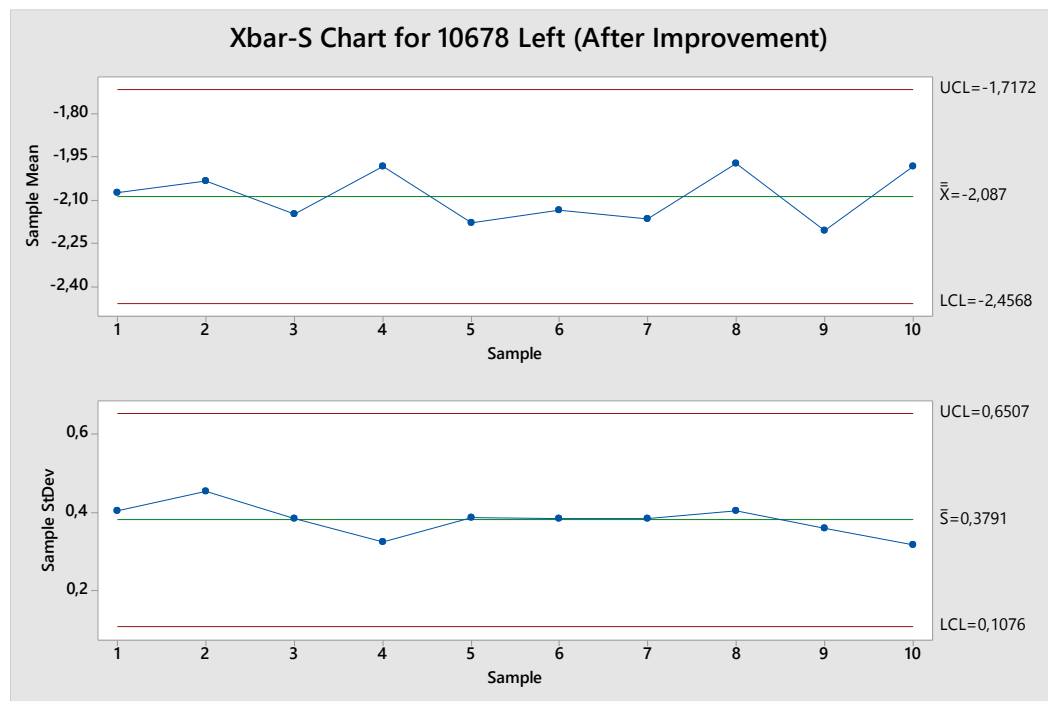

Figure 17. Final $\bar{X}-S$ charts for the component 10678 Left

As a result, it can be concluded that utilization of $100 \%$ virgin polymer pellets in the plastic molding process and preparation of color parameter cards along with operator training substantially improved the process performance.

In addition, cost analysis was conducted to determine the amount of savings attained through the improvement, and thus to establish the financial impact of this study. The unit production cost of defective 10677 right or 10678 left parts to the company is approximately $4 \mathrm{TL}$. Considering this information, the production cost of defective parts, given in Table 8 , is calculated through the formula below:

Production cost of defective parts $=$ Number of defective parts * unit production cost of defective parts

Production cost of defective parts $=$ Number of defective parts $* 4 T L$ 
Table 8

Quantity and cost data for defective parts, prior to improvement

\begin{tabular}{lrrrrr}
\hline Part & $\begin{array}{r}\text { Quantity of } \\
\text { defective } \\
\text { parts / month }\end{array}$ & $\begin{array}{r}\text { Quantity of } \\
\text { defective } \\
\text { parts / year }\end{array}$ & $\begin{array}{r}\text { Cost of } \\
\text { defective } \\
\text { parts / unit } \\
\text { (TL) }\end{array}$ & $\begin{array}{r}\text { Total Cost } \\
\text { (TL/month) }\end{array}$ & $\begin{array}{r}\text { Total Cost } \\
\text { (TL/year) }\end{array}$ \\
\hline 10677 Right & 836.33 & 10035.96 & 4 & 3345.32 & \\
10678 Left & 154.11 & 1849.32 & 4 & 616.44 & 7397.28 \\
& & & Total & 3961.76 & 47541.12 \\
\hline
\end{tabular}

As seen in Table 8, prior to improvement, where melted scrap material was utilized as raw material in the production, there was a total cost of 3961.76 $\mathrm{TL} /$ month for discoloration defects for both right and left parts. This can be expressed as a yearly average cost of 47541.12 TL for discoloration defects occurrence. On the other hand, after the improvement, none of the 140 compiled parts exceeded the specification limits in terms of color grading. Therefore, no defective parts regarding discoloration were found. Based on this, it is determined that the cost of discoloration defect decreased by 3961.76 TL per month. This means a total of $47541.12 \mathrm{TL}$ annual savings due to elimination of discoloration defect.

\section{Conclusion}

\subsection{Implications}

In an effort to reduce environmental impact, defective molded parts can be reused in plastic injection molding. However, this study revealed the fact that for particular products, such as whitecolored home appliance parts, the usage of defective components as raw material inputs is not a feasible approach.

In the white goods industry, aesthetics is among the critical aspects driving customer satisfaction. Fulfillment of aesthetics dimension of quality can produce sustainable competitive advantage through creation of superior value. Accordingly, conformity with design and technical requirements and customer specifications is vital during manufacturing operations. Therefore, perhaps more than in any other industry, minimum aesthetics requirements should be met during household appliances manufacturing operations. For these reasons, in this study it has been determined that conformance to baseline requirements with regards to aesthetics appeal, in our case the color of the components, is important, because aesthetics and appearance of the product creates a direct interface presented to customer. Hence, aesthetics of the product creates either a positive or negative first impression and this initial impression can set the tone for the entire customer-supplier relations. If the product fails to meet the baseline aesthetics features such as coloration issues, the customer may directly reject the shipments. In addition to the rejection of the lots, plastic molded-part suppliers are subject to fees for the shipments containing non-conforming parts. Therefore, in order to avoid such costs and fees, the plastic injection molding companies, especially which are operating in the household appliances industry, should be careful when using defective parts as raw material input in the production of new articles. These companies should utilize virgin polymer/material input as much as possible for better process capability, superior product quality and satisfaction of their customers.

Instead, the defective parts manufactured or scrap plastic materials should be used or recycled using different approaches which require some investment. Different approaches for recycling of scrap material include changing the chemical structure of the scrap polymers with various treatments. Various recycling approaches include restabilization, which protects recycled materials from thermomechanical degradation during reprocessing, or chemical recycling, which includes the recovery of monomers or oligomers by depolymerization actions (e.g. Niaounakis, 2014). The recycled material then can be reused as raw material inputs in the production of new plastic articles or in different areas, such as fiber manufacturing in the clothing and textiles industry or in the consumer electronics products.

Considering these aspects, this study not also guides managers and engineers who work in the plastic injection molding plants in terms of successful Six 
Sigma implementation efforts, but also warns them about reutilization of the scrap material in the production process. By taking into account these warnings, the managers of such plants can avoid waste of time, resources and money that can substantially result from the reutilization of scrap material in a wrong manner. Therefore, reutilization and recycling of scrap plastic material should be well-planned from many aspects.

\subsection{Final Remarks and Future Research Suggestions}

This study presented a detailed application of Six Sigma in a plastic injection molding plant that manufactures and supplies articles for household appliances industry customers. Because quality issues directly affects the performance of the injection molding companies, in this study Six Sigma DMAIC methodology is applied to reduce substantial scrap rates due to discoloration error. Discoloration error was found to stem from the reutilization of scrap plastic material in the production of new parts. Although reprocessing of defective material has benefits of reducing scrap and achieving higher material utilization (e.g. Khavekar et al., 2017), in the current case, reutilization of scrap material, even in small amounts, caused more rejected parts leading to increased scrap rates. Therefore, in this study a systematic Six Sigma DMAIC methodology is applied in order to reduce scrap rates. The initial $3 \sigma$ level of the process performance was improved to $4.7 \sigma$ by means of this study. The goal of the study was achieved via utilization of various Six Sigma tools including Pareto chart, work flow, Measurement System Analysis, control charts, Ishikawa diagram, hypothesis tests and process capability analysis.

Despite the fact that there is a huge body of Six Sigma research testifying its benefits in manufacturing environments, studies that address issues particularly encountered in plastic injection molding processes are limited. In addition to the limited number of direct Six Sigma research on plastic injection molding, there is no distinct Six Sigma research that explicitly improves the aesthetics appeal of the molded plastic products. Therefore, this study tried to fill these gaps that exist in the literature.

Finally, using recycled plastic materials remains a focus of protecting resources and the environment. Recycled plastic has many applications in different sectors. However, recuperation of defective material as the input in injection molding processes, where customer specifications should be strictly met, can generate manufacturing and productquality problems. In this study, such a quality challenge causing aesthetics problems for the product is revealed and eliminated through systematic Six Sigma implementation.

Further research on this particular problem could be conducted with the aim to align the process mean with the target value, as it is not fully centered at the nominal value of the specification interval. Moreover, future in-plant studies could focus on increasing the $P_{p k}$ value to achieve the required 1.33 level. In addition, a small number of other possible causes to discoloration, including equipment characteristics, the cleanness of the molding equipment and not using proper purging compound to remove excess color from the machine, may still present. Improper mixing of the masterbatch or poor thermal stability of the coloring agent are other potential causes to discoloration. These potential causes can be analyzed in detail through Six Sigma DMAIC methodology and addressed in future studies. Similarly, other future Six Sigma projects can be implemented on various other defect types such as burrs or flashes and packaging problems as they constitute a considerable amount within all defects.

In addition to future work suggestions on this particular problem, considering the limited number of quality improvement research on plastic injection molding, further systematic Six Sigma research should be also conducted within the context of this industry. Finally, plastic molded parts used in other industries should be also examined in future studies.

\section{Conflict of Interest}

The authors declared that there is no conflict of interest.

\section{References}

Antony, J., Snee, R., \& Hoerl, R. (2017). Lean Six Sigma: yesterday, today and tomorrow. International Journal of Quality \& Reliability Management, $\quad 34(7), 1073-1093 . \quad$ Doi: https://doi.org/10.1108/IJQRM-03-2016-0035 
Bharti, P., Khan, M., \& Singh, H. (2011). Six Sigma Approach For Quality And Performance Excellence In Plastic Injection Molding IndustryA Case Study And Review. International Journal Of Research In Commerce And Management. 2(2), 58-65.

Birley, A. W. (2012), Plastics Materials: Properties And Applications, Springer Science and Business Media, New York, USA.

Brady, J. E., \&Allen, T. T. (2006). Six Sigma literature: a review and agenda for future research. Quality and Reliability Engineering International, 22(3), 335-367. Doi: https://doi.org/10.1002/qre.769

Desai, D., \& Prajapati, B. N. (2017). Competitive advantage through Six Sigma at plastic injection molded parts manufacturing unit. International Journal of Lean Six Sigma, 8(4), 411-435. Doi: https://doi.org/10.1108/IJLSS-06-2016-0022

Evans, J. R. and Lindsay, W. M. (2014), An Introduction To Six Sigma And Process Improvement, Cengage Learning, Stamford, CT, United States.

Gordon Jr, M. J. (2010), Total Quality Process Control For Injection Molding (Vol. 5), John Wiley and Sons, Hoboken, New Jersey, United States.

Hasan, M. Z., Rahim, M. A., \& Uddin, M. K. (2013) Implementation of Six-Sigma in a CementIndustry, in International Conference on Mechanical, Industrial and Energy Engineering, Khulna, Bangladesh.

Kairulazam, C. K. A. C. K., Hussain, M. I., MohdZain, Z., \&Lutpi, N. A. (2014). Reduction of rejection rate for high gloss plastics product using six sigma method. In Applied Mechanics and Materials (Vol. 606, pp. 141-145). Trans Tech Publications Ltd. Doi: https://doi.org/10.4028/ www.scientific.net/AMM.606.141

Khan, R. M., \& Acharya, G. (2016). Plastic injection molding process and its aspects for quality: a review. European Journal of Advances in Engineering and Technology, 3(4), 66-70.

Khavekar, R., Vasudevan, H., \&Modi, B. (2017). A comparative analysis of Taguchi methodology and Shainin system DoE in the optimization of injection molding process parameters. InIOP Conference Series: Materials Science and Engineering (Vol. 225, No. 1, p. 012183). IOP Publishing.
Kim, J. K., Kim, J. S., Lee, J. H., \& Kwak, J. S. (2017). A Study on Dimension Optimization of Injectionmolded Automotive Bumper by Six Sigma. Journal of the Korean Society of Manufacturing Process Engineers, 16(6), 109-116. Doi: https://doi.org/10.14775/ksmpe.2017.16.6.109

Koh, B. W., Kim, J. S., \& Choi, H. G. (2008). Estimation of Process Parameters Using QFD and Neural Networks in Injection Molding. IE interfaces, 21(2), 221-228.

Lo, W. C., Tsai, K. M., \&Hsieh, C. Y. (2009). Six Sigma approach to improve surface precision of optical lenses in the injection-molding process. The International Journal of Advanced Manufacturing Technology, 41(9), 885-896. Doi: https://doi.org/10.1007/s00170-008-1543-0

Maged, A., Haridy, S., Kaytbay, S., \&Bhuiyan, N. (2019). Continuous improvement of injection moulding using SixSigma: case study. International Journal of Industrial and Systems Engineering, 32(2), 243-266.

Maia, M., Pimentel, C., Silva, F., Godina, R., \&Matias, J. (2019). Order fulfillment process improvement in a ceramic industry. Procedia Manufacturing, 38, 1436-1443. Doi: https://doi.org/10.1016/ j.promfg.2020.01.144

Montgomery, D. C. (2005). Introduction to Statistical Quality Control. John Wiley \& Sons: Hoboken, NJ, USA.

Niaounakis, M. (2014), Biopolymers: Processing and Products, William Andrew, Elsevier, Oxford, United Kingdom.

Rahayu, P. C., \& Darvin, V. (2018). Quality Improvement On Ceramic Tiles Prouction Process with Six Sigma Method (DMAIC) at Pt ArwanaCitramulia. Journal of Industrial Manufacturing, 3(2), Doi: 101-110. http://dx.doi.org/10.31000/jim.v3i2.857

Safwat, T., \& Ezzat, A. (2008, December). Applying Six sigma techniques in plastic injection molding industry. In 2008 IEEE International Conference On Industrial Engineering And Engineering Management (pp. 2041-2045). IEEE. Doi: https://doi.org/10.1109/IEEM.2008.4738230

Timans, W., Ahaus, K., \& Antony, J. (2014). Six Sigma methods applied in an injection moulding company. International Journal of Lean Six 
Sigma, 5(2), 149-167. Doi: https://doi.org/10.1108/IJLSS-07-2013-0037

Uluskan, M. (2016). A comprehensive insight into the Six Sigma DMAIC toolbox. International Journal of Lean Six Sigma, 7(4), 406-429. Doi: https://doi.org/10.1108/IJLSS-10-2015-0040

United States Environmental Protection Agency (EPA) official website (2020), Retrieved from https://www.epa.gov/eg/plastics-molding-andforming-effluent-guidelines 